\title{
A structural basis for the unique binding features of the human vitamin D-binding protein
}

\author{
Christel Verboven, Anja Rabijns, Marc De Maeyer, Hugo Van Baelen, Roger Bouillon and Camiel De Ranter
}

Nature Structural Biology 9, 131-136 (2002).

Two mistakes were introduced during production of this paper. On page 131, in the first paragraph of the introduction, a sentence "The multifunctional DBP also binds monomeric actin (G-actin) and slowly depolymerizes filamentous actin." was inadvertently inserted. The correct version of this part of the introduction should read: "Experiments with DBP knockout mice have shown that DBP protects against dietary vitamin $\mathrm{D}_{3}$ deficiency ${ }^{4}$ In addition, the DBP-25OHD3 complex is reabsorbed in the proximal tubulus by the endocytic receptor megalin ${ }^{6}$."

In Fig. 1, the positions of substituents $\mathrm{R} 2$ and $\mathrm{R} 3$ of the vitamin $\mathrm{D}_{3}$ ligands were incorrectly labeled on the chemical formula. The correct formula is reproduced. We apologize for any confusion these mistakes may have caused.

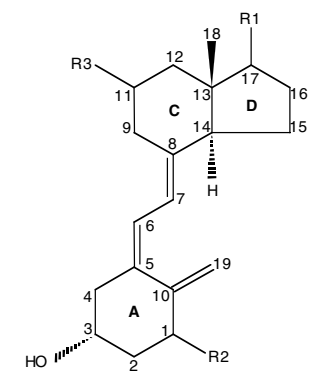

\section{The essential histone variant $\mathrm{H} 2 \mathrm{~A} . \mathrm{Z}$ regulates the equilibrium betw een different chromatin conformational states}

Jun Y. Fan, Faye Gordon, Karolin Luger, J effrey C. Hansen and David John Tremethick

Nature Structural Biology 9, 172-176 (2002).

A problem occurred during the production process of this paper. Consequently, part of Fig. 2 became illegible in print. The entire figure is now reproduced. We apologize for any inconvenience this may have caused.

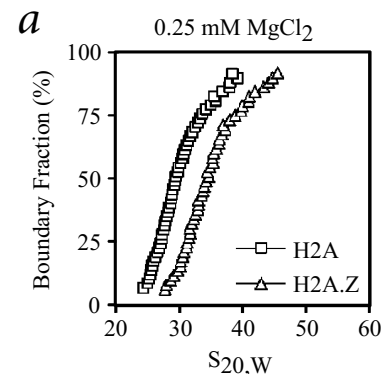

C

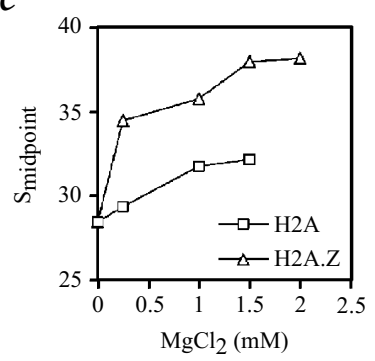

e

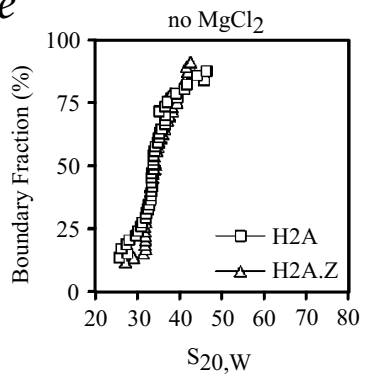

$b$

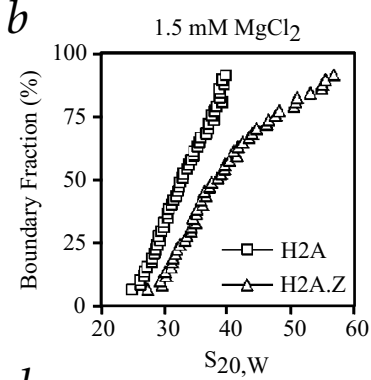

$d$

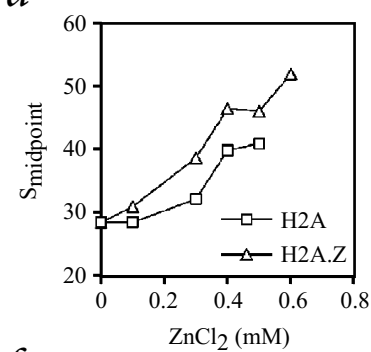

$f$

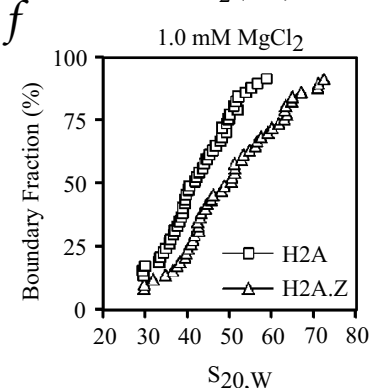

